\title{
Correction to: Grad-Shafranov reconstruction of magnetohydrostatic equilibria with nonisotropic plasma pressure: the theory
}

Wai-Leong Teh ${ }^{*}$ (D)

\section{Correction to: Earth, Planets and Space (2018) 70:34 https://doi.org/10.1186/s40623-018-0802-z}

After publication of this article (Teh 2018), the author has noticed some error with the statement in the abstract and discussion sections. In "Theory" section, $\mathbf{F} \cdot \nabla \alpha=0$ is an assumption to get $\nabla \cdot \mathbf{F}=0$. This assumption leads to $\mathbf{F} \cdot \nabla p_{T}=0$. Therefore, the statement in the abstract and discussion sections that three field-line invariants are found in the system is not correct.

A correct statement is that only one intrinsic fieldline invariant $F_{z}(A)$ exists in the system, while $\alpha(A)$ and $p_{T}(A)$ are assumed. Since the new GS-like equation, Eq. (8) remains unchanged; therefore, the reconstruction does not need auxiliary equations for integration of Eq. (8). It is noteworthy that if $\alpha(A)$ is applied to the equation (A7) of Sonnerup et al. (2006) for magnetohydrostatic conditions, auxiliary equations are still needed for integration of that resulting equation. Moreover, since $\alpha(A)$ and $p_{T}(A)$ are assumed, the reconstruction should be implemented with caution that these two assumptions are reasonably satisfied when applied to the real event studied. The reconstruction results for benchmark case are not affected.
The original article can be found online at https://doi.org/10.1186/s4062 3-018-0802-z.

\section{Publisher's Note \\ Springer Nature remains neutral with regard to jurisdictional claims in pub- lished maps and institutional affiliations.}

Received: 13 November 2018 Accepted: 13 November 2018

Published online: 28 November 2018

\section{Reference}

Teh WL (2018) Grad-Shafranov reconstruction of magnetohydrostatic equilibria with nonisotropic plasma pressure: the theory. Earth Planets Space 70:34. https://doi.org/10.1186/s40623-018-0802-z 